\title{
Polymorphisms in the TJP1 Gene Like a Marker in the High Fitness Performance and Cardiovascular Risk in Athletes; A Law in Training Sport Club-Centers
}

Arturo Caballero-Avendaño ${ }^{1}$, Dalia A Madrigal-Ruiz ${ }^{2}$, Lilian Arzeta-Pino ${ }^{3}$, Jareth Marco Cruz Bastida ${ }^{3}$, Sabina López-Toledo ${ }^{3}$, Melecio Honorio Juarez-Perez ${ }^{3}$, Jhonatan Carlos Castro-Juárez ${ }^{3}$, Claudia, ChavezLopez $^{3}$ and Sergio Alberto Ramirez-Garcia ${ }^{3 *}$

${ }^{1}$ Graduate Studies Division, Master's Program in Public Health, Mexico

${ }^{2}$ Department of Physiology, Immunometabolism and Aging, Mexico

${ }^{3}$ Molecular Biology, Law and Biotechnology in Health Sciences, Mexico

*Corresponding author: Sergio Alberto Ramirez-Garcia, Molecular Biology, Law and Biotechnology in Health Sciences, Mexico University of the Sierra Sur, SUNEO, Oaxaca, Mexico.
Received Date: February 27, 2020

Published Date: March 10, 2020

\section{Opinion}

The TJP1 gene is a very important gene that can be used as a molecular marker of physical performance, as it has been shown to participate in the absorption of nutrients at the level of intestinal villi (glucose, lipids, solutes, among others) both at paracellular level as in the basement membrane of these cells, which is very important at a nutritional level because a good intestinal absorption ensures a better nutritional status, which favors having better macro and micronutrient reserves, which is a determining factor for high performance

However, this is a frontier of research, since there are no studies of sports genetics focused on the analysis of polymorphisms in this gene in relation to physical performance, nutritional status, quality of nutritional intake or factors of body composition. And more if we consider that Type 1 narrow junctions, which are encoded by this gene are very important to maintain the architecture and cell differentiation wich are very important at two levels at the level of adipose tissue and at the level of the precursor cells of the arcuate nucleus. In this case, if they have an adequate structure, on the one hand there is an adequate reserve and oxidation of fats in the adipose tissue, and on the other hand it maintains the architecture of the arcuate nucleus, which allows adequate function of the orexigenic and anorexigenic pathway, regulating satiety as well as hunger. Both factors allow to determine a better physical body composition and utilization of fat from adipose tissue, such as muscle fat $[1,2]$.

Certainly, there are few variants that have been studied of the narrow type 1 Union, but it is a virgin field for geneticists and molecular biologists who are dedicated to the study of body composition. In this sense, genetic marker of the gene that leads to amino acid changes, such as polymorphism rs229166, leads to a conformational change in the $\mathrm{ZO}-1$ structure, which is realetd to the albuminuria [3]. One of those polymorphisms is rs1038306187 leading to the change of amino acid p. Gln791Glu in the domain guanylate kinase. The domain ZU5 has 33 polymorphisms leading to conformational changes. The polymorphisms that affect gene expression by nucleotide changes at the cryptic sites of the alternative splicing are rs781148827, rs5478300017, rs78014403 and rs1020739943 in acceptor region, and rs1029122894 in the donor region, but none of these polymorphisms have been explored for their pathogenic effect. Due to effect on ZO-1 expression, they are a new frontier of research in the also fitness performance [4].

On the other hand, polymorphic markers of this gene could be very useful too in the detection of cardiovascular problems or arrhythmias such as arrhythmogenic dysplasia, which are a very important cause of sudden death in many athletes and highperformance athletes. The association with these conditions can 
make it possible to detect people at risk before death during routine training or during the performance of sports activity [5].

Undoubtedly, the detection of the markers of the TJP1 gene in athlets can be very useful as a law or a health policy in centers and sports clubs for the prevention of deaths due to cardiovascular problems, or to select sports talents with greater physical abilities and sports.

\section{Acknowledgement}

None.

\section{Conflicts of Interest}

No conflicts of interest.

\section{References}

1. Ramirez Garcia SA, Flores Alvarado LJ, Topete Gonzalez LR, Charles Nino C, Mazariegos Rubi M, et al. (2016) High frequency of ancestral allele of the TJP1 polymorphism rs2291166 in Mexican population, conformational effect and applications in surgery and medicine. Cir Cir 84(1): 28-36.

2. Ramirez Bohorquez E, Garcia Cruz D, Ortega Pacheco D, Siliceo-Murrieta JI, Ramon Canul LG, et al. (2018) Clinical implications of the expression of genes that code for tight junction proteins: the case of tjp1. Journal of Biochemical Education (REB) 37(3): 67-74.

3. Lehman DM, Leach RJ, Johnson Pais T, Hamlington J, Fowler S, et al. (2006) Evaluation of tight junction protein 1 encoding zona occludens 1 as a candidate gene for albuminuria in a Mexican American population. Exp Clin Endocrinol Diabetes 114(8): 432-437.

4. Aguilar ME, Perla M Madrigal Ruiz, Flores Alvarado LJ, Ruiz R, Parada F, et al. (2018) Tight junction protein 1 gene in neurodegenerative disease, new frontier. MOJ Gerontol Ger 3(1): 51-52

5. De Bortoli M, Postma A, Poloni G, Calore M, Minervini G, et al. (2018) Whole-Exome Sequencing Identifies Pathogenic Variants in TJP1 Gene Associated with Arrhythmogenic Cardiomyopathy. Circulation: Genomic and Precision Medicine 11(10) 